\title{
Do leukocytes have a role in the cerebral no-reflow phenomenon?
}

\author{
B S ASPEY, C JESSIMER, S PEREIRA, M J G HARRISON \\ From the Department of Neurological Studies, University College and Middlesex School of Medicine, \\ London, UK
}

SUMMARY The possible role of leukocytes in the cerebral microcirculation following ischaemia was assessed in the gerbil. The no-reflow phenomenon seen after 30 minutes of severe bilateral hemispheric ischaemia during hypotensive reperfusion was compared in control animals and in a group made leukopenic by pretreatment with cyclophosphamide. Neither the incidence nor the severity of the no-reflow phenomenon differed between the two groups. The evidence from this study casts doubt on the hypothesis that leukocyte plugging plays a major role in the cerebral microcirculation's response to ischaemia.

There is increasing interest in the rheological properties of leukocytes. ${ }^{1}$ The peripheral blood leukocyte count has been shown to be a predictor of myocardial infarction, and stroke, ${ }^{2-6}$ and leukocyte counts correlate with the size of myocardial infarcts. ${ }^{7}$ A poor prognosis after myocardial infarction, ${ }^{89}$ and stroke ${ }^{10}$ is associated with a high leukocyte count. In experimental models of myocardial infarction, reducing the leukocyte count reduces infarct size." The role of leukocytes in the cerebral circulation has received less attention, ${ }^{12}$ but cellular plugging has been suggested as a contributory factor in the genesis of the "no-reflow" phenomenon. ${ }^{13}$ This is characterised by patchy poor perfusion after arrest of the cerebral circulation, if reperfusion is initially at an untreated low perfusion pressure. ${ }^{14}$

We sought to investigate the role of leukocytes in the cerebral circulation by studying the effect of lowering the peripheral blood leukocyte count on the development of the no-reflow phenomenon in the gerbil brain.

\section{Methods}

The no-reflow phenomenon was produced in the gerbil by 30 minutes of severe bilateral hemispheric ischaemia followed

Address for reprint requests: Dr M J G Harrison, Department of Neurological Studies, Middlesex Hospital School of Medicine, Mortimer Street, London WIN 8AA, UK.

Received 12 August 1988 and in revised form 19 November 1988. Accepted 28 November 1988

by reperfusion without blood pressure support. Adult gerbils of either sex $(60-80 \mathrm{~g})$ were anaesthetised with intraperitoneal pentobarbitone $60 \mathrm{mg} / \mathrm{kg}$ (Sagatal May and Baker Ltd). Through a midline cervical incision a tracheostomy was performed and both common carotid arteries were isolated with 5-0 silk sutures. A cannula was placed in the left femoral artery for blood sampling and continuous blood pressure monitoring. The left femoral vein was cannulated for injection of India ink. Arterial blood $(0 \cdot 1 \mathrm{ml})$ was removed for measurement of leukocyte count and haematocrit and in some of the animals a platelet count. ${ }^{15}$ Scoville-Lewis aneurysm clips were then placed on both carotid arteries for 30 minutes. Ten minutes after their removal, an intravenous injection of $1 \mathrm{ml}$ of an isotonic filtered suspension of India ink was given over the course of 30 seconds. (Pulmonary filtration further removes larger particles and the cerebral microcirculation is thereby fully perfused.) This technique also ensures that the intravascular marker circulates at the prevailing arterial blood pressure. After a further minute of reperfusion with India ink the animal was decapitated and the brain removed and fixed in $10 \%$ neutral formal saline. Coronal $(1 \mathrm{~mm})$ sections were dehydrated in alcohol and cleared in oil of Wintergreen (methyl salicylate) for subsequent visual inspection. Brain slices were reviewed without access to other data and the degree of capillary filling recorded as normal or abnormal. Abnormal patterns were further divided into four grades.

Grade 1 Minimal abnormality

Grade 2 Mild abnormality

Grade 3 Moderate abnormality
Occasional cortical radial capillaries unfilled.

Small areas of cortical \&/or subcortical non-filling.

Confluent areas of cortical and subcortical non-filling. 
Table 1 Blood pressure levels $(\mathrm{mm} \mathrm{Hg}+\mathrm{sd})$ to nearest $5 \mathrm{~mm}$

\begin{tabular}{llll}
\hline Group & Pre-occl. & During occl. & $\begin{array}{l}\text { During } \\
\text { reperfusion }\end{array}$ \\
\hline $\begin{array}{l}\text { Cyclo } \\
(\mathrm{n}=15)\end{array}$ & $55+15$ & $80+20$ & $40+15$ \\
$\begin{array}{c}\text { Saline } \\
(\mathrm{n}=17)\end{array}$ & $65+10$ & $80+20$ & $50+15$ \\
\hline
\end{tabular}

Grade 4 Severe abnormality

Extensive areas of poor perfusion including cortex subcortex \& basal ganglia.

Two groups of gerbils were subjected to severe bilateral hemispheric ischaemia in this manner. The first group received four consecutive daily intraperitoneal injections of cyclophosphamide $50 \mathrm{mg} / \mathrm{kg}$ (Farmitalia, Carlo Erba Ltd) in order to suppress their peripheral blood leukocyte count. Control animals received the same number of injections of normal saline. At the time of each injection an additional intraperitoneal injection of "Mesna" (sodium 2 mercaptoethanesulphonate WB Pharmaceuticals Ltd) $50 \mathrm{mg} / \mathrm{kg}$ was given to limit the nephrotoxic effects of cyclophosphamide. Controls also received injections of "Mesna". All animals were anaesthetised for surgery the day after the last injections.

\section{Results}

In two animals the India ink perfusion was unsuccessful for technical reasons, and in five others the blood pressure did not fall below their starting blood pressure on clip removal. Under these circumstances the no-reflow phenomenon does not develop, ${ }^{14}$ so these animals were excluded. Blood pressure changes were comparable in the two groups with the characteristic response to bilateral carotid clipping of a sustained increase in pressure during occlusion and a fall after clip removal (table 1). Cyclophosphamide injections in 15 animals lowered the whole blood leukocyte count by $85 \%$ with much smaller changes in platelet count and haematocrit (table 2). Seventeen controls completed the protocol.

The no-reflow phenomenon was observed in 10 of the cyclophosphamide treated animals and 13 of the controls (table 3 ). This difference is not significant, and the ratings of severity by the blinded observer showed no difference between the two groups.

Table 2 Haematological values (mean $+s d)$

\begin{tabular}{llc}
\hline & \multicolumn{2}{c}{ Cyclophosphamide (15) Controls (17) } \\
\hline WBC $10^{9} / 1$ & $0.89+0.61$ & $6 \cdot 13+4 \cdot 12 \ddagger$ \\
Platelets $10^{11} / 1$ & $4 \cdot 49+1.38(\mathrm{n}=5)$ & $6 \cdot 17+1 \cdot 66^{*}(\mathrm{n}=9)$ \\
HCT\% & $34.5+3.5$ & $39 \cdot 5+5.0 \dagger$ \\
\hline *NS. & \\
$\dagger \mathrm{p}<0.01$. & \\
$\ddagger \mathrm{p}<0.001$. &
\end{tabular}

Table 3 Incidence and severity of no-reflow

\begin{tabular}{lll}
\hline Grade & Cyclophosphamide & Control \\
\hline Normal & 5 & 4 \\
1 & 1 & 1 \\
2 & 2 & 4 \\
3 & 4 & 5 \\
4 & 3 & 3 \\
Total & 15 & 17 \\
\hline
\end{tabular}

\section{Discussion}

This study has failed to reveal any evidence that a grossly reduced leukocyte count reduces the incidence or severity of the no-reflow phenomenon in the gerbil brain subjected to 30 minutes of severe bilateral hemispheric ischaemia. The marrow suppression produced by the cyclophosphamide also reduced platelet numbers and haematocrit though to a smaller extent. These effects might also have been expected to improve perfusion as haemodilution can reduce the no-reflow phenomenon, ${ }^{13}$ and the presence of platelet aggregates is believed to be a contributory factor in obstructing the lumen of small vessels for example after myocardial infarction. ${ }^{16}$

When Fischer and Ames first described the noreflow phenomenon they saw it as a critical factor in the brain's peculiar sensitivity to ischaemia. ${ }^{13}$ They thought that the mechanism underlying the impaired perfusion of the brain had to do with endothelial changes or glial cell swelling. Subsequently cellular plugging of capillaries has been considered at least as important with evidence of increased viscosity in stagnant blood, platelet and red cell aggregation, and leukocyte plug formation. ${ }^{13}{ }^{17}$ The present results suggest that leukocyte numbers are not critical to development of the no-reflow phenomenon. This makes a rheological explanation for the epidemiological evidence of leukocyte involvement in cerebrovascular disease somewhat less likely.

There is of course a chicken and egg argument over the finding of an increased stroke mortality in those with a high leukocyte count, ${ }^{10}$ or with abnormal leukocyte rheology after acute stroke. ${ }^{18} 19$ The blood changes may be part of the stress response which also elevates fibrinogen and erythrocyte sedimentation rate. ${ }^{20}$ Only interventional studies could determine whether the peripheral leukocytosis is pathologically significant in acute stroke victims. The present study lends little support to such a proposal.

\section{References}

1 Lowe G. Blood rheology in arterial disease. Clin Sci 1986;71:137-46.

2 Friedman GD, Klatsky AL, Siegelaub AB. The leukocyte 
count as predictor of myocardial infarction. $N$ Eng $J$ Med 1974;290:1275-8.

3 Zalokar JB, Richard JL, Claude JR. Leukocyte count, smoking, and myocardial infarction. $N$ Eng $J$ Med 1981;304:465-8.

4 Grimm RM, Neaton JD, Ludwig W. Prognostic importance of white blood cell count for coronary, cancer, and all cause mortality. JAMA 1985;254:1932-7.

5 Harrison MJG, Marshall J. Does the peripheral blood leukocyte count predict the risk of transient ischaemic attacks and strokes? J Neurol Neurosurg Psychiatry 1987;50:1558-9.

6 Prentice RL, Szatrowski TP, Kato H, Mason MW. Leukocyte counts and cerebrovascular disease. J Chron Dis 1982;35:703-14.

7 Dintenfass L, Forbes CD. GOT, GPT, and LDH levels and blood viscosity factors after recent myocardial infarction: effect of ABO blood groups. Haematologia 1974;8:523-33.

8 Haines AP, Howarth D, North WRS, et al. Haemostatic variables and the outcome of myocardial infarction. Thromb Haemost 1983;50:800-3.

9 Schlant RC, Forman S, Stamler J, Canner PL. The natural history of coronary heart disease: prognostic factors after recovery from myocardial infarction in 2789 men. Circulation 1982;66:401-14.

10 The National Institute of Neurological and Communicative Disorders and Stroke. The national survey of stroke. Stroke 1981;12 suppl:23-4.

11 Romson JL, Hook BG, Rinkel SL, Abrams ED, Shork MA, Lucchesi BR. Reduction of the extent of ischemic myocardial injury by neutrophil depletion in the dog. Circulation 1983;67:1016-23.

12 Yamakawa T. Dynamics of white blood cells and red blood cells in microcirculatory networks of the cat brain cortex during haemorrhagic shock: intravital microscopic study. Microvasc Res 1982;24:218.

13 Fischer EG, Ames A. Studies on mechanisms of impairment of cerebral circulation following ischaemia: effect of haemodilution and perfusion pressure. Stroke 1972; 3:538-42.

14 Harrison MJG, Sedal L, Arnold J, Ross Russel RW. Noreflow phenomenon in the cerebral circulation of the gerbil. J Neurol Neurosurg Psychiatry 1975;38:1190-3.

15 Baker FJ, Silverton RE. Introduction to Medical Laboratory Technology. London: Butterworths, 1985.

16 Haerem JW. Platelet aggregates in intramyocardial vessels of patients dying suddenly and unexpectedly of coronary artery disease. Atherosclerosis 1972;15: 199-213.

17 Tomita M, Gotoh F, Amano T, Tanabashi N, Tamaka K. "Low perfusion hyperemia" following middle cerebral arterial occlusion in cats of different age groups. Stroke 1980;11:629-36.

18 Ernst E, Matrai A, Paulsen F. Leukocyte rheology and recent stroke. Stroke 1987;18:59-62.

19 Ciuffetti G, Mercuri M. Palozzetti D, Lombardini R. Leukocyte rheology and recent stroke. Stroke 1988; 19:122-3.

20 Fletcher AP, Alkjaersig N, Davies A, et al. Blood coagulation and plasma fibrinolytic enzyme system pathophysiology in stroke. Stroke 1976;7:337-48. 